\title{
Systemic Inflammatory Response Markers and CA-125 Levels in Ovarian Clear Cell Carcinoma: A Two Center Cohort Study
}

\author{
Hee Seung Kim, MD ${ }^{1,2}$ \\ Hwa-Young Choi, MD ${ }^{1}$ \\ Maria Lee, MD' \\ Dong Hoon Suh, MD ${ }^{3}$ \\ Kidong Kim, MD, $\mathrm{PhD}^{3}$ \\ Jae Hong No, MD, PhD ${ }^{3}$ \\ Hyun Hoon Chung, MD, PhD ${ }^{1}$ \\ Yong Beom Kim, MD, PhD 3 \\ Yong Sang Song, MD, $\mathrm{PhD}^{1,2,4}$
}

\begin{abstract}
Purpose
We compared the predictive and prognostic values of leukocyte differential counts, systemic inflammatory (SIR) markers and cancer antigen 125 (CA-125) levels, and identified the most useful marker in patients with ovarian clear cell carcinoma (OCCC).
\end{abstract}

\section{Materials and Methods}

The study included 109 patients with OCCC who did not have any inflammatory conditions except endometriosis, and underwent primary debulking surgery between 1997 and 2012. Leukocyte differential counts (neutrophil, lymphocyte, monocyte, eosinophil, basophil, and platelet), SIR markers including neutrophil to lymphocyte ratio (NLR), monocyte to lymphocyte ratio (MLR), and platelet to lymphocyte ratio (PLR), and CA-125 levels were estimated to select potential markers for clinical outcomes.

\section{Results}

Among potential markers (neutrophil, monocyte, platelet, NLR, MLR, PLR, and CA-125 levels) selected by stepwise comparison, CA-125 levels were best at predicting advanced stage disease, suboptimal debulking and platinum-resistance (cut-off values, $\geq 46.5, \geq 11.45$, and $\geq 66.4 \mathrm{U} / \mathrm{mL}$; accuracies, $69.4 \%, 78.7 \%$, and 68.5\%) while PLR $\geq 205.4$ predicted noncomplete response (CR; accuracy, 71.6\%) most accurately. Moreover, PLR < 205.4 was an independent factor for the reduced risk of non-CR (adjusted odds ratio, 0.17; 95\% confidence interval [CI], 0.04 to 0.69), and NLR $<2.8$ was a favorable factor for improved progression-free survival (PFS; adjusted hazard ratio, 0.49; 95\% $\mathrm{Cl}, 0.25$ to 0.99) despite lack of a marker for overall survival among the potential markers.

\section{Conclusion}

CA-125 levels may be the most useful marker for predicting advanced-stage disease. Suboptimal debulking and platinum-resistance, and PLR and NLR may be most effective to predict non-CR and PFS in patients with OCCC.

\section{Key words}

Clear cell adenocarcinoma, Ovarian neoplasms, CA-125 antigen, Neutrophils, Blood platelets, Lymphocytes

\section{Introduction}

Ovarian clear cell carcinoma (OCCC) is the fourth most common of histologic types of epithelial ovarian cancer (EOC). OCCC prognosis is similar to other histologic types in early-stage disease but it has the worst prognosis in advanced stage disease [1]. In general, about two-thirds of patients with EOC including OCCC have advanced stage disease at diagnosis because the disease is typically symptomless and there is no effective screening method [2], resulting in 5-year survival of $18.6 \%$ in patients with advancedstage disease [1]. To monitor tumor response and confirm relapse in patients with EOC, cancer antigen 125 (CA-125) levels are a highly useful surrogate in the clinical setting [3]

However, the prognostic value of CA-125 levels is less clear in OCCC. A limited number of studies found that CA-125 levels were lower in OCCC than in other histologic 
types, and did not reflect clinical outcomes of patients with OCCC $[4,5]$. To overcome these limitations, there is a growing interest in systemic inflammatory response (SIR) markers such as leukocyte differential counts to predict clinical outcomes in patients with EOC, because various types of malignancy are associated with systemic inflammation, which may contribute to secondary hematologic abnormalities $[6,7]$. SIR markers, including neutrophil to lymphocyte ratio (NLR), monocyte to lymphocyte ratio (MLR), and platelet to lymphocyte ratio (PLR), may be useful to predict clinical outcomes in patients with EOC $[8,9]$. Nevertheless, most pertinent studies included different histologic types of EOC, while there is a lack of studies where the efficacy of SIR markers was investigated in patients with OCCC. Thus, we conducted the current study to compare the predictive and prognostic values among leukocyte differential counts, SIR markers and CA-125 levels, and thereby to identify the most useful marker in patients with OCCC.

\section{Materials and Methods}

\section{Study population}

We collected clinico-pathologic data from a database of EOC registered from Seoul National University Hospital and Seoul National University Bundang Hospital between February 1997 and December 2012. The Institutional Review Board at our institution approved the current study, and the informed consent requirement was waived because the current study was conducted by a retrospective medical record review.

We included only patients with OCCC who underwent primary debulking surgery. Leukocyte differential counts including neutrophil, lymphocyte, monocyte, platelet, basophil, and eosinophil, SIR markers such as NLR, MLR, and PLR, CA-125 levels were measured within one week before staging laparotomy. However, patients with any inflammatory conditions or other malignancies that could affect the results of laboratory tests were excluded, except endometriosis proved by biopsy. Clinico-pathologic data collected included age, International Federation of Gynecology and Obstetrics (FIGO) stage, endometriosis, extent of debulking surgery, regimen and cycles of adjuvant chemotherapy, leukocyte differential counts, SIR markers, CA-125 levels, tumor response, platinum-resistance, progression-free survival (PFS), and overall survival (OS).

\section{Data extraction}

Leukocyte differential counts were estimated 1 week prior to surgery (SYSMEX XE-2100, TOA Medical Electronics, Kobe, Japan), and CA-125 levels were measured at the same time using a radioimmunoassay kit (Fujirebio Diagnostics, Malvern, PA). Optimal debulking was defined as a residual tumor $\leq 1 \mathrm{~cm}$ in a maximal diameter, and complete response (CR) was defined as the disappearance of all tumor burdens for at least 4 weeks with normalization of CA-125 levels. PFS was calculated as the time elapsed from the date of completion of primary treatment to the date of clinically proven recurrence, and platinum-resistance was defined as PFS less than 6 months. OS was defined as the length of time from the date of surgery to the date of cancer-related death or the end of study.

\section{Statistical analysis}

We compared leukocyte differential counts, SIR markers and CA-125 levels based on clinico-pathologic characteristics using Student's $t$ test and Mann-Whitney U test in patients with OCCC, and selected potential markers associated with the clinico-pathologic characteristics among them. We calculated the best cut-off values of potential markers based on the receiver operating characteristic (ROC) curve, and assessed the sensitivity (SN), specificity (SP), positive predictive value (PPV), negative predictive value (NPV), and accuracy to identify the best marker for predicting clinical outcomes.

Next, we investigated the best prognostic factors among the potential markers for tumor response and survival in the patients. To this end, we performed logistic regression and Cox's proportional hazard analyses, and calculated odds ratio (OR), hazard ratio (HR) and 95\% confidence interval (CI). Statistical analyses were performed with SPSS ver. 19.0 (SPSS Inc., Chicago, IL). We rejected null hypotheses of no difference if p-values were less than 0.05 , or, equivalently, if the $95 \%$ CIs of risk point estimates excluded 1.

\section{Results}

\section{Patient characteristics}

One hundred and nine patients with OCCC were included, and Table 1 shows their clinico-pathologic characteristics. The median age was 53 years (range, 30 to 86 years), and the median duration of follow-up was 46 months (range, 6.1 to 192.9 months). One hundred and one patients $(92.6 \%)$ had 
Table 1. Clinico-pathologic characteristics of 109 patients with ovarian clear cell carcinoma

\begin{tabular}{lc} 
Characteristic & No. of patients $(\%)$ \\
Age (yr) & \\
$<54$ & $57(52.3)$ \\
$\geq 54$ & $52(47.7)$ \\
FIGO stage & $68(62.4)$ \\
I-II & $41(37.5)$ \\
III-IV & \\
Histology & $101(92.6)$ \\
Pure & $8(7.4)$ \\
Mixed & \\
Endometriosis & $62(56.9)$ \\
No & $47(43.1)$ \\
Yes & \\
Optimal debulking & $95(87.2)$ \\
No & $14(12.8)$ \\
Yes & \\
Regimen of chemotherapy & $6(5.5)$ \\
No & $17(15.6)$ \\
Non-taxane and platinum & $86(78.9)$ \\
Taxane and platinum & \\
Cycles of chemotherapy & $93(85.3)$ \\
$\leq 6$ & $16(14.7)$ \\
$6-9$ & $89(81.7)$ \\
Platinum-resistance & $20(18.3)$ \\
No & \\
Yes & $89(81.7)$ \\
Tumor response & \\
Non-CR & \\
CR & \\
\hline
\end{tabular}

FIGO, International Federation of Gynecology and Obstetrics; $\mathrm{CR}$, complete response.

pure OCCC, whereas, of those with mixed OCCC, three $(2.8 \%)$ had endometrioid and serous types, three $(2.8 \%)$ endometrioid type, and two (1.8\%) serous type in addition to clear cell carcinoma. After primary treatment, 89 patients $(81.7 \%)$ showed CR while four (3.7\%) demonstrated partial response, two $(1.8 \%)$ had stable disease, and $14(12.8 \%)$ suffered disease progression.

\section{Prediction}

When we compared leukocyte differential counts, SIR markers and CA-125 levels based on clinico-pathologic characteristics, neutrophila, monocytosis, thrombocytosis, elevated NLR, PLR, and CA-125 levels were associated with advanced-stage disease, non-CR, and platinum-resistance. Thrombocytosis, elevated NLR, PLR, and CA-125 levels were associated with suboptimal debulking, and elevated MLR was associated with non-CR and platinum-resistance (Table 2). We calculated the best cut-off values of the potential markers selected in Table 2 by ROC curves, and assessed SN, SP, PPV, NPV, and accuracy (Fig. 1). CA-125 levels were best at predicting advanced-stage disease $(\geq 46.5 \mathrm{U} / \mathrm{mL})$, suboptimal debulking $(\geq 11.45 \mathrm{U} / \mathrm{mL})$ and platinum-resistance $(\geq 66.4 \mathrm{U} / \mathrm{mL})$, while PLR $\geq 205.4$ predicted non-CR most accurately (Table 3 ).

\section{Prognosis}

To determine the best prognostic factors among the potential markers, we performed logistic regression analyses, which showed that optimal debulking (adjusted OR, 0.02; 95\% CI, 0.01 to 0.12 ) and PLR < 205.4 (adjusted OR, 0.17; 95\% $\mathrm{CI}, 0.04$ to 0.69 ) were independent factors associated with the reduced risk of non-CR (Table 4). In terms of survival, earlystage disease, optimal debulking, taxane- and platinumbased chemotherapy and NLR $<2.8$ were favorable factors for improved PFS (adjusted HRs, 0.18, 0.37, 0.36, and 0.49; $95 \%$ CIs, 0.08 to $0.41,0.16$ to $0.84,0.15$ to 0.89 , and 0.25 to 0.99 ) while early-stage disease and optimal debulking were favorable factors for improved OS (adjusted HRs, 0.08 and 0.26; $95 \%$ CIs, 0.03 to 022 and 0.09 to 0.75 ) (Table 5).

\section{Discussion}

SIR involves secondary changes in the levels of circulating leukocytes, which show neutrophilia, monocytosis, lymphocytopenia and thrombocytosis [10]. Thus, some leukocyte differential counts and SIR markers have been studied in relation with EOC because leukocyte-mediated inflammatory cytokines by tumor would inhibit apoptosis and promote angiogenesis, resulting in tumor growth, progression and metastasis [11]. In particular, neutrophilia, lymphocytopenia, NLR and PLR are prognostic of advance-stage disease, residual disease after surgery and survival in patients with EOC-like CA-125 levels [12-16].

In the current study, CA-125 levels were best for predicting advanced-stage disease, suboptimal debulking and platinum-resistance in patients with OCCC. Although most leukocyte differential counts and SIR markers were statistically significant for predicting advanced-stage disease, suboptimal debulking and platinum-resistance, we found that CA-125 levels had the highest SN, SP, PPV, NPV, and accuracy. Specific leukocyte differential counts (neutrophil, monocyte, and platelet), and SIR markers (NLR, MLR, and PLR) increase proportionally with a growing burden of 


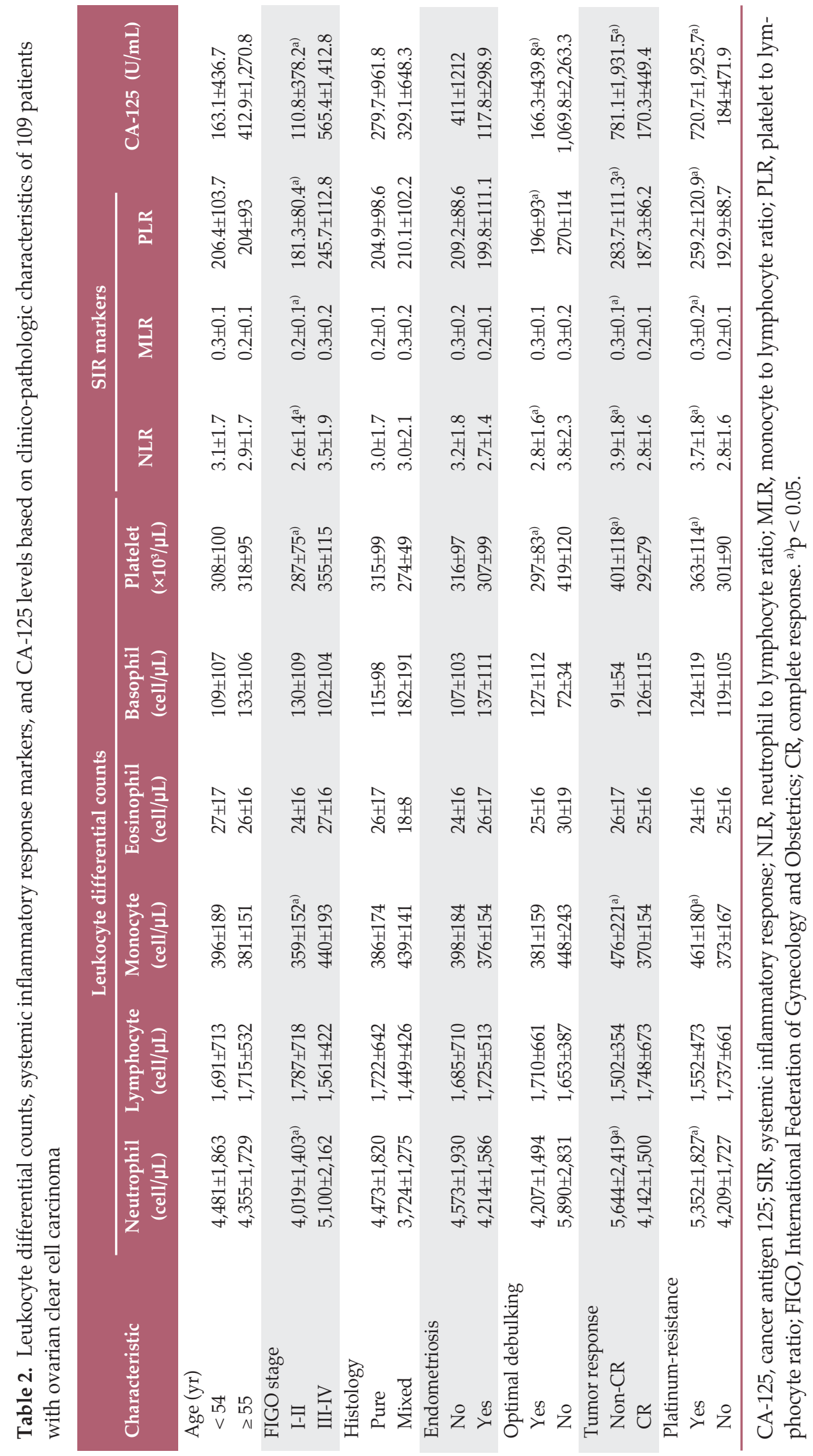



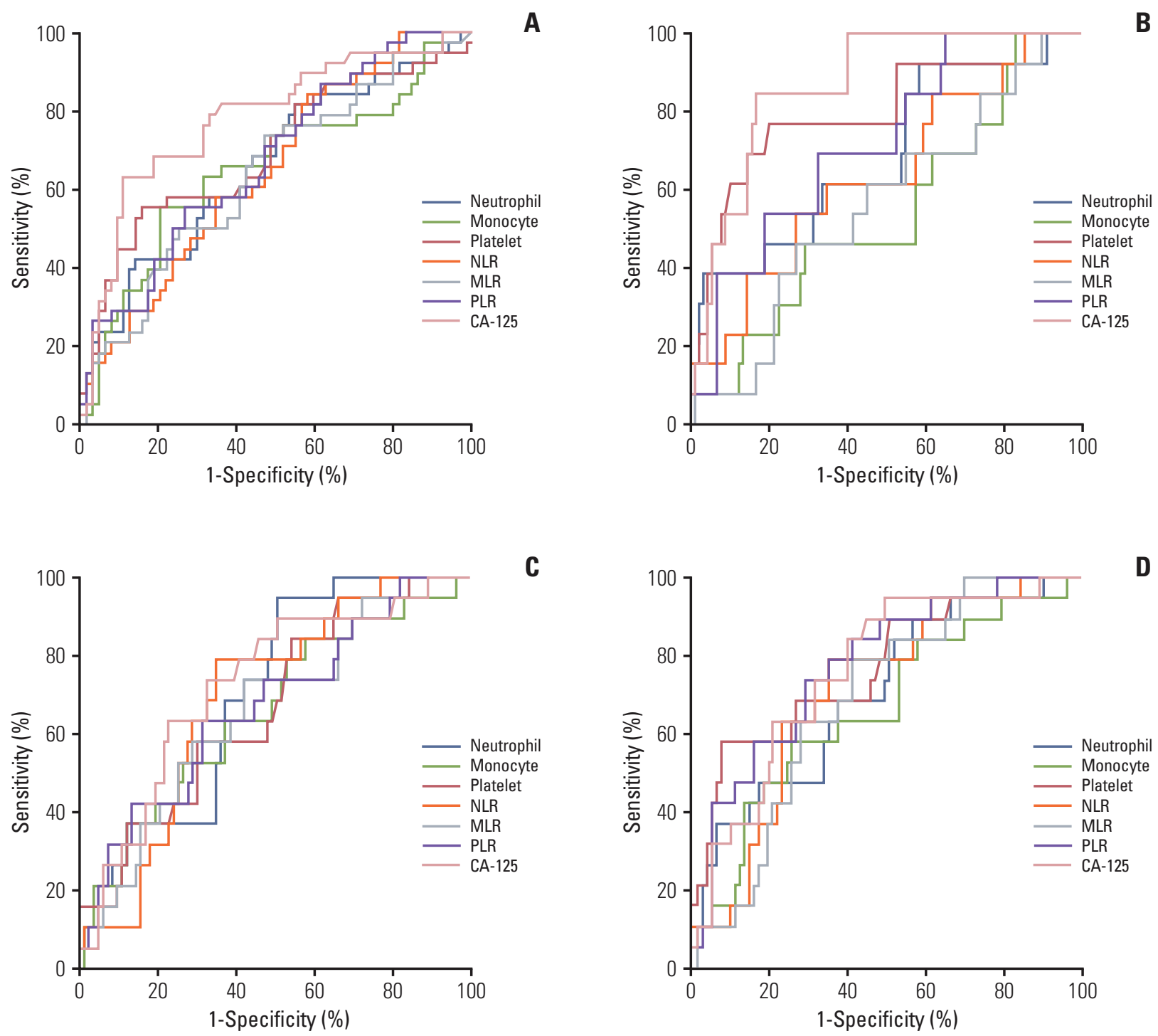

Fig. 1. The receiver operating characteristic curves to determine the best cut-off values of leukocyte differential counts including neutrophil, monocyte and platelet, neutrophil to lymphocyte ratio (NLR), monocyte to lymphocyte ratio (MLR), platelet to lymphocyte ratio (PLR), and cancer antigen 125 (CA-125) levels for predicting International Federation of Gynecology and Obstetrics (FIGO) stage III-IV disease (A), suboptimal debulking (B), platinum-resistance (C), and non-complete response (D) in 109 patients with ovarian clear cell carcinoma.

inflammation such as cancer, whereas CA-125 levels are relatively low in early-stage OCCC in comparison with other histologic types of EOC because of the apparent initial smaller volume of disease as well as fundamental differences in the biology of malignancy $[4,12,17]$. However, CA-125 levels increase in advanced-stage disease because of an increase of tumor burden [18]. Thus, high levels of CA-125 can predict advanced-stage disease or suboptimal debulking more accurately compared with elevation of specific leuko- cyte differential counts and SIR markers. This hypothesis is supported indirectly by a study that found CA-125 levels to be a sensitive biomarker of tumor response in low-grade serous carcinoma showing a low level of CA-125 [19].

Furthermore, PLR was the most significant to predict tumor response after primary treatment among the potential markers. Platelets interact with tumor cells, and to contain factors contributing to tumor growth, invasion and angiogenesis [20]. Moreover, it can protect tumor cells from natu- 
Table 3. SN, SP, PPV, NPV, and accuracy of leukocyte differential counts, systemic inflammatory response markers, CA-125 levels by the receiver operating characteristic curve

\begin{tabular}{|c|c|c|c|c|c|c|c|c|}
\hline Characteristic & Cut-off value & AUC & SN $(\%)$ & SP $(\%)$ & PPV $(\%)$ & NPV $(\%)$ & Accuracy $(\%)$ & p-value \\
\hline \multicolumn{9}{|c|}{ FIGO stage III-IV disease } \\
\hline Neutrophil (cell/ $\mu \mathrm{L})$ & $\geq 4,370$ & 0.66 & 60.5 & 59.4 & 46.9 & 71.7 & 59.8 & $<0.01$ \\
\hline Monocyte $($ cell $/ \mu \mathrm{L})$ & $\geq 389$ & 0.65 & 65.8 & 64.6 & 52.1 & 76.4 & 65 & 0.01 \\
\hline Platelet $\left(\times 10^{3} / \mu \mathrm{L}\right)$ & $\geq 300$ & 0.70 & 60.5 & 57.8 & 46 & 71.2 & 58.8 & $<0.01$ \\
\hline NLR & $\geq 2.4$ & 0.65 & 60.5 & 56.3 & 45.1 & 70.6 & 57.8 & 0.01 \\
\hline MLR & $\geq 0.2$ & 0.64 & 60.5 & 60 & 46.9 & 72.2 & 60.2 & 0.02 \\
\hline PLR & $\geq 178.3$ & 0.68 & 60.5 & 57.8 & 46 & 71.2 & 58.8 & $<0.01$ \\
\hline CA-125 (U/mL) & $\geq 46.5$ & 0.78 & 73.2 & 67.2 & 57.7 & 80.4 & 69.4 & $<0.01$ \\
\hline \multicolumn{9}{|l|}{ Suboptimal debulking } \\
\hline Neutrophil (cell / $\mu \mathrm{L}$ ) & $\geq 4,254$ & 0.69 & 61.5 & 50.6 & 15.4 & 90 & 51.9 & 0.03 \\
\hline Monocyte (cell / $\mu \mathrm{L}$ ) & $\geq 354$ & 0.54 & 61.5 & 43.3 & 13.6 & 88.6 & 45.6 & 0.65 \\
\hline Platelet $\left(\times 10^{3} / \mu \mathrm{L}\right)$ & $\geq 295$ & 0.80 & 76.9 & 51.7 & 18.9 & 93.9 & 54.9 & $<0.01$ \\
\hline NLR & $\geq 2.4$ & 0.64 & 61.5 & 50.6 & 15.4 & 90 & 52 & 0.11 \\
\hline MLR & $\geq 0.2$ & 0.56 & 61.5 & 54.4 & 16.3 & 90.7 & 55.3 & 0.49 \\
\hline PLR & $\geq 205.4$ & 0.72 & 69.2 & 67.4 & 23.7 & 93.8 & 67.6 & 0.01 \\
\hline CA-125 (U/mL) & $\geq 114.5$ & 0.87 & 78.6 & 78.7 & 35.5 & 96.1 & 78.7 & $<0.01$ \\
\hline \multicolumn{9}{|l|}{ Non-CR } \\
\hline Neutrophil (cell / $\mu \mathrm{L})$ & $\geq 4,428$ & 0.71 & 68.4 & 62.7 & 29.5 & 89.7 & 63.7 & $<0.01$ \\
\hline Monocyte $($ cell $/ \mu \mathrm{L})$ & $\geq 394$ & 0.67 & 63.2 & 63.1 & 27.9 & 88.3 & 66 & 0.03 \\
\hline Platelet $\left(\times 10^{3} / \mu \mathrm{L}\right)$ & $\geq 297$ & 0.77 & 73.7 & 54.2 & 26.9 & 90 & 57.8 & $<0.01$ \\
\hline NLR & $\geq 2.7$ & 0.71 & 73.7 & 65.1 & 32.6 & 91.5 & 66.7 & $<0.01$ \\
\hline MLR & $\geq 0.3$ & 0.69 & 68.4 & 63.1 & 29.5 & 89.8 & 64.1 & $<0.01$ \\
\hline PLR & $\geq 205.4$ & 0.78 & 73.7 & 71.1 & 36.8 & 92.2 & 71.6 & $<0.01$ \\
\hline CA-125 (U/mL) & $\geq 66.9$ & 0.76 & 70 & 69.3 & 34.1 & 69.3 & 69.4 & $<0.01$ \\
\hline \multicolumn{9}{|l|}{ Platinum-resistance } \\
\hline Neutrophil (cell/ $\mu \mathrm{L})$ & $\geq 4,436$ & 0.70 & 63.2 & 62.7 & 27.9 & 88.1 & 62.7 & $<0.01$ \\
\hline Monocyte $($ cell $/ \mu \mathrm{L})$ & $\geq 394$ & 0.65 & 63.2 & 63.1 & 27.9 & 88.3 & 63.1 & 0.04 \\
\hline Platelet $\left(\times 10^{3} / \mu \mathrm{L}\right)$ & $\geq 297$ & 0.67 & 63.2 & 51.8 & 23.1 & 86 & 53.9 & 0.02 \\
\hline NLR & $\geq 2.8$ & 0.69 & 68.4 & 65.1 & 31 & 90 & 65.7 & $<0.01$ \\
\hline MLR & $\geq 0.3$ & 0.66 & 63.2 & 61.9 & 27.3 & 88.1 & 62.1 & 0.03 \\
\hline PLR & $\geq 178.3$ & 0.67 & 68.4 & 55.4 & 26 & 88.5 & 57.8 & 0.02 \\
\hline CA-125 (U/mL) & $\geq 66.4$ & 0.73 & 70 & 68.2 & 33.3 & 90.9 & 68.5 & $<0.01$ \\
\hline
\end{tabular}

$\mathrm{SN}$, sensitivity; SP, specificity; PPV, positive predictive value; NPV, negative predictive value; AUC, area under curve; FIGO, International Federation of Gynecology and Obstetrics; NLR, neutrophil to lymphocyte ratio; MLR, monocyte to lymphocyte ratio; PLR, platelet to lymphocyte ratio; CA-125, cancer antigen 125.

ral killer cell-mediated lysis, thereby facilitating metastasis [21]. Thus, thrombocytosis is also common in patients with EOC [13]. Since tumor cells secret thrombopoietic cytokines such as interleukin-6, thrombocytosis is related to poor response in solid tumors, combined with lymphocytopenia [22]. In the current study, we found PLR, among the potential markers, to be a better predictor of risk of non-CR in patients with OCCC, like previous studies $[9,13]$. However, all potential markers have modest predictive values to determine tumor response in patients with OCCC because common mechanisms lead to their coincident elevation. Thus, more focused studies are required to validate the role of PLR to predict tumor response in the patients.

Last, NLR was the most important prognostic factor for PFS despite there being no marker related to OS among the potential markers. Many studies reports that a higher neutrophil count or a lower lymphocyte predicts poorer survival in EOC [12]. Among blood components, the potential mechanism underlying the prognostic value of NLR may be an association between high NLR and inflammation. Neutrophilia produces inflammatory cytokines and chemokines by both the tumor and associated host cells such as leuko- 
Table 4. Prognostic factors associated with the reduced risk of non-complete response after primary treatment in 109 patients with ovarian clear cell carcinoma

\begin{tabular}{|c|c|c|c|c|c|c|}
\hline \multirow{2}{*}{ Factor } & \multicolumn{3}{|c|}{ Univariate } & \multicolumn{3}{|c|}{ Multivariate } \\
\hline & OR & $95 \% \mathrm{CI}$ & p-value & Adjusted OR & $95 \% \mathrm{CI}$ & p-value \\
\hline Age $<54$ yr & 0.70 & $0.26-1.85$ & 0.47 & - & - & - \\
\hline FIGO stage I-II disease & 0.07 & $0.02-0.24$ & $<0.01$ & - & - & - \\
\hline Pure OCCC & 0.65 & $0.12-3.49$ & 0.62 & - & - & - \\
\hline Optimal debulking & 0.02 & $0.01-0.08$ & $<0.01$ & 0.02 & $0.01-0.12$ & $<0.001$ \\
\hline $\begin{array}{l}\text { Taxane- and platinum-based } \\
\text { chemotherapy }\end{array}$ & 0.61 & $0.16-2.29$ & 0.46 & - & - & - \\
\hline$>6$ cycles of chemotherapy & 0.42 & $0.13-1.40$ & 0.16 & - & - & - \\
\hline PLR $<205.4$ & 0.15 & $0.05-0.45$ & $<0.01$ & 0.17 & $0.04-0.69$ & 0.01 \\
\hline CA-125 < $66.9(\mathrm{U} / \mathrm{mL})$ & 0.19 & $0.07-0.55$ & $<0.01$ & - & - & - \\
\hline
\end{tabular}

OR, odds ratio; CI, confidence interval; FIGO, International Federation of Gynecology and Obstetrics; OCCC, ovarian clear cell carcinoma; PLR, platelet to lymphocyte ratio; CA-125, cancer antigen 125.

Table 5. Prognostic factors related with improved progression-free and overall survivals in 109 patients with ovarian clear cell carcinoma

\begin{tabular}{|c|c|c|c|c|c|c|}
\hline \multirow{2}{*}{ Factor } & \multicolumn{3}{|c|}{ Univariate } & \multicolumn{3}{|c|}{ Multivariate } \\
\hline & HR & $95 \% \mathrm{CI}$ & p-value & Adjusted HR & $95 \% \mathrm{CI}$ & p-value \\
\hline \multicolumn{7}{|l|}{ Progression-free survival } \\
\hline Age $<54$ yr & 1.14 & $0.60-2.17$ & 0.68 & - & - & - \\
\hline FIGO stage I-II disease & 0.15 & $0.08-0.31$ & $<0.01$ & 0.18 & $0.08-0.41$ & $<0.01$ \\
\hline Pure OCCC & 0.56 & $0.20-1.59$ & 0.28 & - & - & - \\
\hline Optimal debulking & 0.13 & $0.06-0.27$ & $<0.01$ & 0.37 & $0.16-0.84$ & 0.02 \\
\hline $\begin{array}{l}\text { Taxane- and platinum-based } \\
\text { chemotherapy }\end{array}$ & 0.87 & $0.41-1.84$ & 0.72 & 0.36 & $0.15-0.89$ & 0.03 \\
\hline$>6$ cycles of chemotherapy & 1.79 & $0.82-3.93$ & 0.14 & - & - & - \\
\hline NLR $<2.8$ & 0.34 & $0.18-0.67$ & $<0.01$ & 0.49 & $0.25-0.99$ & 0.04 \\
\hline CA-125 < $68.5(\mathrm{U} / \mathrm{mL})$ & 0.29 & $0.15-0.57$ & $<0.01$ & - & - & - \\
\hline \multicolumn{7}{|l|}{ Overall survival } \\
\hline Age $<54$ yr & 2.00 & $0.85-4.69$ & 0.11 & - & - & - \\
\hline FIGO stage I-II disease & 0.12 & $0.05-0.30$ & $<0.01$ & 0.08 & $0.03-0.22$ & $<0.01$ \\
\hline Pure OCCC & 0.53 & $0.16-1.78$ & 0.30 & - & - & - \\
\hline Optimal debulking & 0.14 & $0.06-0.36$ & $<0.01$ & 0.26 & $0.09-0.75$ & 0.01 \\
\hline $\begin{array}{l}\text { Taxane- and platinum-based } \\
\text { chemotherapy }\end{array}$ & 0.69 & $0.29-1.65$ & 0.40 & - & - & - \\
\hline$>6$ cycles of chemotherapy & 3.06 & $1.31-7.13$ & 0.10 & - & - & - \\
\hline NLR $<2.8$ & 0.29 & $0.13-0.68$ & $<0.01$ & - & - & - \\
\hline CA-125 < $68.5(\mathrm{U} / \mathrm{mL})$ & 0.26 & $0.11-0.59$ & $<0.01$ & - & - & - \\
\hline
\end{tabular}

HR, hazard ratio; CI, confidence interval; FIGO, International Federation of Gynecology and Obstetrics; OCCC, ovarian clear cell carcinoma; NLR, neutrophil to lymphocyte ratio; CA-125, cancer antigen 125.

cytes, and contributes to malignant progression by secreting tumor growth factors such as vascular endothelial growth factor [11]. However, neutrophilia as an inflammatory response by cancer inhibits the immune system by suppress- ing the cytotoxic activity of immune cells such as lymphocytes and natural killer cells [23]. NLR reflects these inflammatory changes, and therefore may be a useful marker in patients with a cancer for which reliable biomarkers are lack- 
ing [24]. A recent meta-analysis reported a similar result in that NLR was related to a higher risk of mortality than PLR in solid tumors because the broader properties of neutrophils, in comparison with platelets, may stimulate various cytokines [25]. Nevertheless, no potential markers have a significant impact on OS in the current study, which requires a new biomarker for predicting OS in the patients.

Whether the potential markers can be applied to predict clinical outcomes in patients with OCCC is controversial. Although recent meta-analyses emphasized the importance of SIR markers to predict prognosis of solid tumors, research that interprets their usefulness in EOC when compared with other malignancies is lacking $[24,25]$. Furthermore, OCCC cases in most studies comprise a small proportion, $5 \%-8 \%$, among patients with EOC, making it difficult to evaluate prognostic values of the potential markers in patients with OCCC $[4,19]$.

\section{Conclusion}

Although the current study has some limitations such as a retrospective design and unassessed possible confounders affecting SIR (e.g., smoking or oral contraceptive use) [12], we included a large number of patients with OCCC, and sought to identify the most dominant markers related to clinical outcomes by stepwise comparison of prognostic values among the potential markers. Conclusively, CA-125 levels may be the most useful marker for predicting advancedstage disease, suboptimal debulking and platinum-resistance, and PLR and NLR may be the most effective to predict non-CR and PFS in patients with OCCC.

\section{Conflicts of Interest}

Conflict of interest relevant to this article was not reported.

\section{Acknowledgments}

This research was supported by grants (No. 04-2012-0890; 03-2012-0170) from the Seoul National University Hospital research fund, and the Priority Research Centers Program (No. 2009-0093820), Basic Science Research Program (No. 2011-0025394), and BK21 plus program (No. 5256-20140100) through the National Research Foundation of Korea (NRF) funded by the Ministry of Education, Science and Technology. Moreover, it was also supported by a grant of the Korean Health Technology R\&D Project, Ministry of Health of Welfare (HI14C2404).

\section{References}

1. Suh DH, Kim JW, Kang S, Kim HJ, Lee KH. Major clinical research advances in gynecologic cancer in 2013. J Gynecol Oncol. 2014;25:236-48.

2. Kim JH, MacLaughlin DT, Donahoe PK. Mullerian inhibiting substance/anti-Mullerian hormone: A novel treatment for gynecologic tumors. Obstet Gynecol Sci. 2014;57:343-57.

3. Rustin GJ, Vergote I, Eisenhauer E, Pujade-Lauraine E, Quinn M, Thigpen T, et al. Definitions for response and progression in ovarian cancer clinical trials incorporating RECIST 1.1 and CA 125 agreed by the Gynecological Cancer Intergroup (GCIG). Int J Gynecol Cancer. 2011;21:419-23.

4. Tian C, Markman M, Zaino R, Ozols RF, McGuire WP, Muggia FM, et al. CA-125 change after chemotherapy in prediction of treatment outcome among advanced mucinous and clear cell epithelial ovarian cancers: a Gynecologic Oncology Group study. Cancer. 2009;115:1395-403.

5. Eltabbakh GH, Mount SL, Beatty B, Simmons-Arnold L, Cooper K. Clinical and molecular differences between clear cell and papillary serous ovarian carcinoma. J Surg Oncol. 2006;93:379-86.

6. Shan W, Yang G, Liu J. The inflammatory network: bridging senescent stroma and epithelial tumorigenesis. Front Biosci (Landmark Ed). 2009;14:4044-57.

7. den Ouden M, Ubachs JM, Stoot JE, van Wersch JW. Whole blood cell counts and leucocyte differentials in patients with benign or malignant ovarian tumours. Eur J Obstet Gynecol Reprod Biol. 1997;72:73-7.

8. Kim SI, Kim HS, Kim TH, Suh DH, Kim K, No JH, et al. Impact of underweight after treatment on prognosis of advancedstage ovarian cancer. J Immunol Res. 2014;2014:349546.

9. Asher V, Lee J, Innamaa A, Bali A. Preoperative platelet lymphocyte ratio as an independent prognostic marker in ovarian cancer. Clin Transl Oncol. 2011;13:499-503.

10. Jilma B, Blann A, Pernerstorfer T, Stohlawetz P, Eichler HG, Vondrovec B, et al. Regulation of adhesion molecules during human endotoxemia. No acute effects of aspirin. Am J Respir 
Crit Care Med. 1999;159:857-63.

11. Balkwill F, Mantovani A. Inflammation and cancer: back to Virchow? Lancet. 2001;357:539-45.

12. Williams KA, Labidi-Galy SI, Terry KL, Vitonis AF, Welch WR, Goodman A, et al. Prognostic significance and predictors of the neutrophil-to-lymphocyte ratio in ovarian cancer. Gynecol Oncol. 2014;132:542-50.

13. Raungkaewmanee S, Tangjitgamol S, Manusirivithaya S, Srijaipracharoen S, Thavaramara T. Platelet to lymphocyte ratio as a prognostic factor for epithelial ovarian cancer. J Gynecol Oncol. 2012;23:265-73.

14. Cho H, Hur HW, Kim SW, Kim SH, Kim JH, Kim YT, et al. Pre-treatment neutrophil to lymphocyte ratio is elevated in epithelial ovarian cancer and predicts survival after treatment. Cancer Immunol Immunother. 2009;58:15-23.

15. Milne K, Alexander C, Webb JR, Sun W, Dillon K, Kalloger SE, et al. Absolute lymphocyte count is associated with survival in ovarian cancer independent of tumor-infiltrating lymphocytes. J Transl Med. 2012;10:33.

16. Bishara S, Griffin M, Cargill A, Bali A, Gore ME, Kaye SB, et al. Pre-treatment white blood cell subtypes as prognostic indicators in ovarian cancer. Eur J Obstet Gynecol Reprod Biol. 2008;138:71-5.

17. Ho CM, Chien TY, Shih BY, Huang SH. Evaluation of complete surgical staging with pelvic and para-aortic lymphadenectomy and paclitaxel plus carboplatin chemotherapy for improvement of survival in stage I ovarian clear cell carcinoma. Gynecol Oncol. 2003;88:394-9.
18. Behbakht K, Randall TC, Benjamin I, Morgan MA, King S, Rubin SC. Clinical characteristics of clear cell carcinoma of the ovary. Gynecol Oncol. 1998;70:255-8.

19. Fader AN, Java J, Krivak TC, Bristow RE, Tergas AI, Bookman $\mathrm{MA}$, et al. The prognostic significance of pre- and post-treatment CA-125 in grade 1 serous ovarian carcinoma: a gynecologic Oncology Group study. Gynecol Oncol. 2014;132:560-5.

20. Jain S, Harris J, Ware J. Platelets: linking hemostasis and cancer. Arterioscler Thromb Vasc Biol. 2010;30:2362-7.

21. Nieswandt B, Hafner M, Echtenacher B, Mannel DN. Lysis of tumor cells by natural killer cells in mice is impeded by platelets. Cancer Res. 1999;59:1295-300.

22. Buergy D, Wenz F, Groden C, Brockmann MA. Tumor-platelet interaction in solid tumors. Int J Cancer. 2012;130:2747-60.

23. Gooden MJ, de Bock GH, Leffers N, Daemen T, Nijman HW. The prognostic influence of tumour-infiltrating lymphocytes in cancer: a systematic review with meta-analysis. Br J Cancer. 2011;105:93-103.

24. Templeton AJ, McNamara MG, Seruga B, Vera-Badillo FE, Aneja P, Ocana A, et al. Prognostic role of neutrophil-to-lymphocyte ratio in solid tumors: a systematic review and metaanalysis. J Natl Cancer Inst. 2014;106:dju124.

25. Templeton AJ, Ace O, McNamara MG, Al-Mubarak M, VeraBadillo FE, Hermanns T, et al. Prognostic role of platelet to lymphocyte ratio in solid tumors: a systematic review and meta-analysis. Cancer Epidemiol Biomarkers Prev. 2014;23: 1204-12. 